\title{
Always the Bridesmaid and never the Bride! Arts, Archaeology and the E-Science Agenda
}

\author{
Prof. Vincent Gaffney \\ Insitute of Archaeology and Antiquity \\ University of Birmingham, Edgbaston, Birmingham, B15 2TT, United Kingdom \\ E-mail:v.1.gaffney@bham.ac.uk
}

\author{
Dr. R. P. Fletcher ${ }^{1}$ \\ Computing Service \\ University of York, Heslington, York, YO10 5DD, United Kingdom \\ E-mail: R.Fletcher@york.ac.uk
}

\begin{abstract}
There is, without doubt, a strong tradition amongst the Arts and Humanities community of the gifted individuals: academics who can, and do, labour long and hard alone in libraries or museums, to provide significant scholarly works. The creation and organisation of large data sets, the desire for enhanced accessibility to data held in disparate locations and the increasing complexity of our theoretical and methodological aspirations inevitably push us towards greater use of technology and a reliance on interdisciplinary teams to facilitate their use. How far such a process has become established, however, is a moot point. As the director of one Arts-based Visualisation laboratory[1] that possesses an UKlight connection, I would probably observe that the Arts and Humanity community has, largely, remained aloof from many of the recent developments of large-scale, ubiquitous technologies, with the notable exception of those that permit resource discovery. It remains a fact that the emergence, for instance, of GRID technologies in other disciplines has not yet had the impact one might have expected on Arts and Humanities. It seems certain that reticence has not been the consequence of a lack of data within the Arts. Others, including archaeology, sit at the edge of the natural sciences and are prodigious generators of data in their own right, or consumers of digital data generated by other disciplines. Another assertion that may be considered is that Arts research is not amenable to large-scale distributed computing. To a certain extent, successful Grid applications are linked to the ability of researchers to agree methodologies that, to some extent, permit a "mechanistic" world view that is amenable to such analysis. However, in contrast it is not true that Arts research is either so individual, so chaotic or anarchic that it is impossible to demonstrate the value, at least, of e-science applications to our disciplines.
\end{abstract}

Lighting the Blue Touchpaper for UK e-Science - Closing Conference of ESLEA Project The George Hotel, Edinburgh, UK

26-28 March, 200

\footnotetext{
$1 \quad$ Speaker
} 


\section{Introduction}

Potential Arts and Humanities E-research activities can be broken down, in general terms, as shown in Figure 1 and one suspects that most researchers would be comfortable with the assertion of one or more of these general themes as being central to their own work.

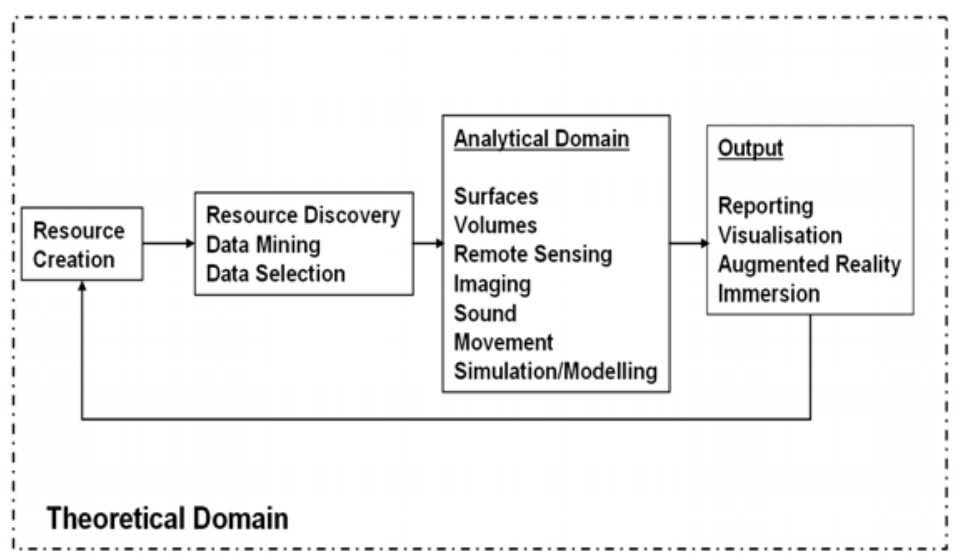

Figure 1. e-Research Activities

Visualisation, an area of specific interest for my own area of research (Landscape Archaeology), may be regarded as a useful point of departure in considering where the Arts stand in respect of forming an E-Science agenda and whether it may move towards a proportionate use of available technology, including high volume, low latency networks. Aside from the technical aspect of visualisation, visualisation carries the implication of being, in most senses, a final act within a larger research process that has involved the collection, selection and manipulation of data in some iterative manner.

\section{Discussion}

For the Arts the act of visualisation, therefore, carries considerable theoretical or methodological baggage. Intellectually the act of visualisation is a highly emotive act and, within archaeology at least, there has been considerable debate as to the legitimacy of visualisation as an isolated output. This is hardly surprising in a society in which dazzling imagery is ubiquitous and pervades everyday life. However, for historical disciplines it has particular significance. By definition, our reality is usually a degraded image of an original that has eroded or rotted away, or the proxy representation of past events through surviving records written, frequently, by people who never witnessed the events far from the places they lived. The impact that virtual reconstructions may have on the observer is inevitably more real than the heap of rocks and lines of postholes that we encounter daily on archaeological sites or the dry, detailed footnotes of a historical text. Media representations of historical events and archaeology in particular, seem particularly open to virtual representation and, perhaps, misrepresentation. In this context, we might consider the example of a digital model[2] of a Wild Goat style cup, see Figure 2, created from an original in the Museum of the Institute of 
Archaeology at Birmingham. The cup itself is a relatively simple stemmed vessel and of interest mainly because of the suggestion that the painted design might indicate that the vessel was a skeuomorph whose metal prototype possessed incised angular designs that were repeated in paint on the clay copy. Some time ago, this cup was scanned and rendered with an image of the surface design. This model was used, with the surface of the design raised, to create a casting in metal but the digital model was also rendered haptically to permit the user to view the digital model either as metal or clay. The significance of the exercise was not so much the ingenuity of permitting visitors to touch, virtually, an object that would otherwise have only been experienced through the glass of a museum case: rather it was the fact that the visitor experienced an enhanced act of interpretation. It may be that there never was a metal original of the stemmed cup and its representation (digital or physical), remains an act of subtle imagination. The experience of interpretation is therefore a central role of visualisation rather than the simple representation of any particular reality.

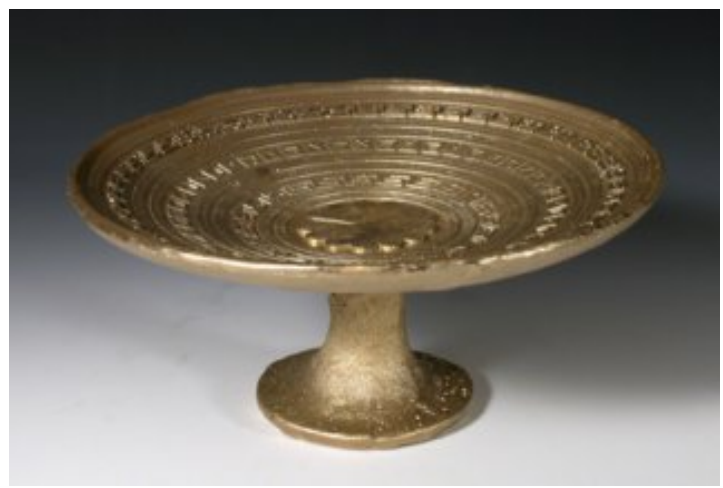

Figure 2. Wild Goat style cup

The environment itself is a physical and viewable research asset that requires incorporation within interpretative schema. Imbued with meaning, we now study our physical and natural context in its own right and appreciate the ability of landscapes to manipulate human action as a consequence merely of its existence. There is an important point to be made here and that is, with respect to landscape, the significance of the new technologies is not simply power, but the application of the continuous measurement and analysis of space and the extension of the analytical sphere to virtually every part of a landscape may be equally significant. If so this means that the Arts will increasingly stray into the area of the environment, the natural sciences and, by implication, will therefore appropriate demands for substantial computing power.

Over the next 5 years or so one can predict that the emergent technologies for 3D landscape scanning from ground or air-base platforms[3] will further transform our capacity for control of space, filling the gap between ground-based geophysics and traditional aerial photography, through the reproduction of the surface of the landscape in an almost seamless fashion. Alternately, consider the potential of work piloted by Ian Haynes, with a Birmingham group at the Lateran where physical reconstruction of the superstructure of the church is 
incorporated with volumetric rendering of data from ground penetrating radar to provide a wider interpretative context of this internationally important building.

However, infinitely finessing the resolution of data itself cannot satisfy our disciplinary aspirations to explain the past. Physical scale can become a driving force in its own right. The example here can be of route analysis which might vary in scale between local paths beside a farm to trade routes that span continents. Although analysis of any of these communication routes may be quite simplistic in itself the potential of scale, but also resolution, as a driver of computational need should be clear.

However, nothing demonstrates this more dramatically, perhaps than the Birmingham project on the Palaeolandscapes of the Southern North Sea.[4] This project seeks to explore the land inundated by the sea during the last great period of global warming. Between the end of the last glacial maximum and c. 6,000 BC an area larger than England was lost to the sea. This great plain was probably the heartland of the Mesolithic populations of North Western Europe. Man lived and walked the rivers and valleys of this country and the hills and the plains have since been lost beneath a remorseless onslaught of water. Today, we can barely trace the outline of this vast landscape. This month a research team in Birmingham, funded by the Aggregates Levy Sustainability Fund, is concluding the mapping of more than 20,000 $\mathrm{km}^{2}$ of this landscape using 3-dimensional seismic data collected for the purposes of oil and gas exploration and provided by PGS. This is an archaeo-geophysical survey the size of the whole of Wales, see Figure 3. Using this data we have begun to trace, and even to name, the rivers, hills and valleys that have been lost to mankind for more than eight millennia, see Figure 4. We have not yet begun to finesse this relatively course data with the thousands of 2D lines, cores, borehole data, and the steps to recreate this lost world have begun to involve immersive VR, and intelligent life modelling. The past is not a foreign country it is an imaginary one, but that does not absolve us from the responsibility to study and learn from it.

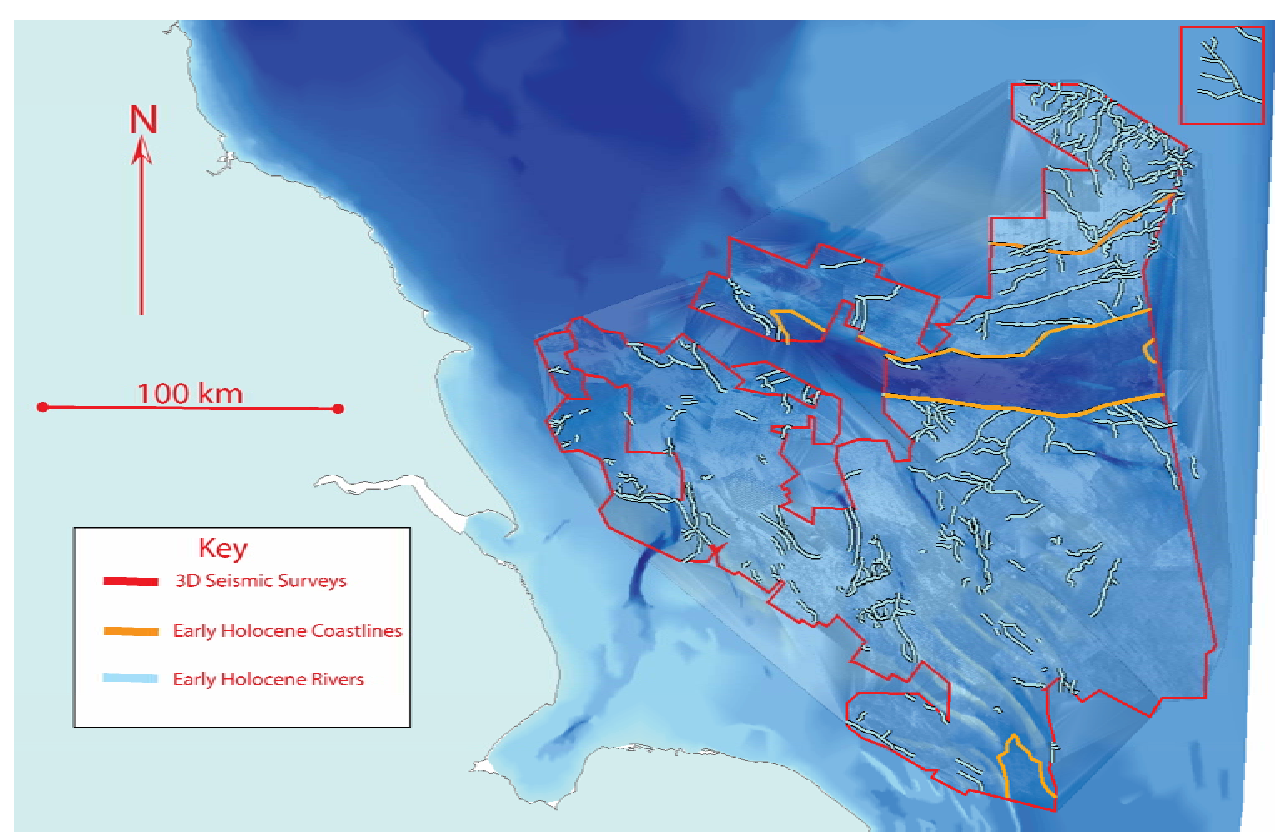

Figure 3. Area of Study 


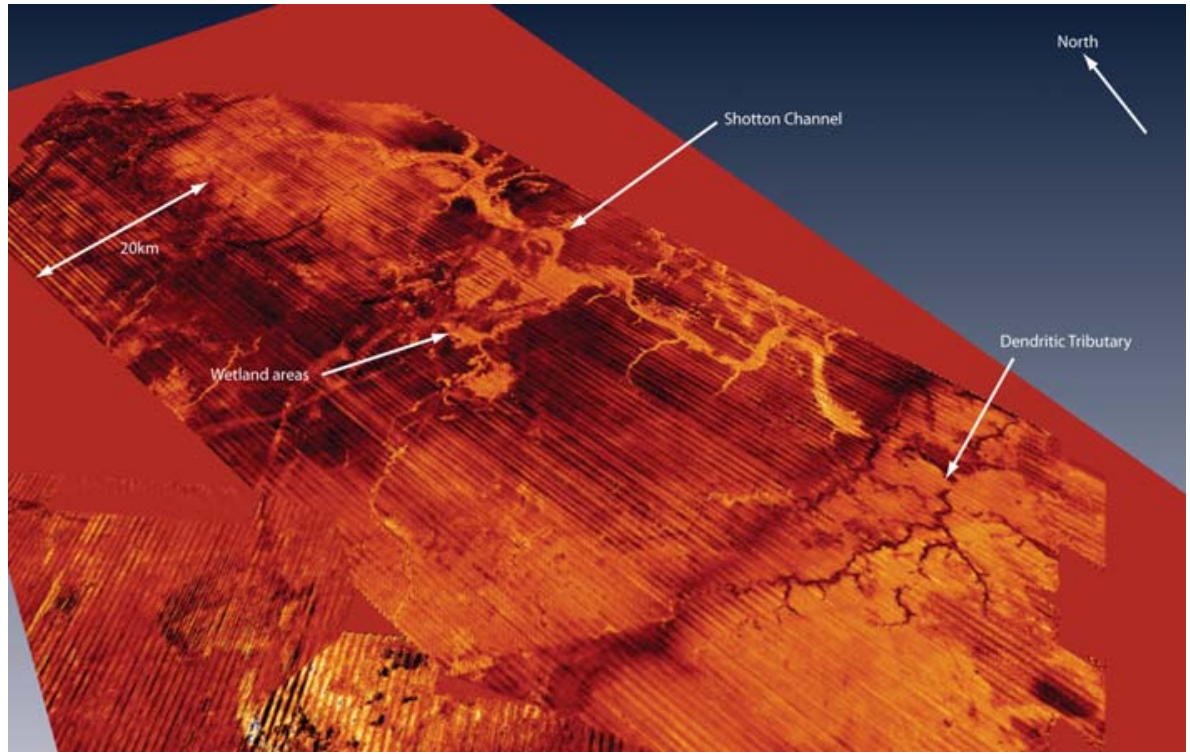

Figure 4 Rivers, Hills and Valleys

The intellectual freedom that is demanded for Arts projects, and the range of legitimate research routes to provide provisional statements, requires flexibility and the imaginative use of available technologies. However, whilst flexibility and imagination are desirable qualities in general, the intellectual and technological landscape relating to visualisation looks to have more in common with the Wild West rather than the Arcadian backdrop often more suitable for a considered national research strategy. Despite this, it is appropriate that some statement is made on both the practise and principles regarding ICT development in the Arts and Humanities. There are a number of specific points that I would also raise under these headings.

The number of groups that are currently involved in large-scale e-science programmes within the Arts is relatively small, nationally or internationally, and it is unlikely that any specific group will establish complete competence across the range of technologies likely to be used or be able to provide appropriate resource for all potential projects. However, it is critical that the United Kingdom possesses and develops the potential of existing expertise. Integrative technologies, most notably the Access Grid, perhaps linked with virtual network computing, will be central to linking the increasingly disparate groups that are required to study project which span the Arts and natural Sciences. Powerful low latency networks such as UKLight, with near seamless computing capabilities, may become central to development of distributed research programmes dealing with significant shared data sets. Integration with monuments, dress, and reception studies, particularly in Classics or Ancient History probably demand high quality photorealistic representation. The capacity for immersive replication of human movement is likely to become significant over time and appropriate data capture facilities and rendering capacity will follow from this.

Following this, I think it equally appropriate to highlight a number of strategic issues. It is essential for the Arts that technology is adopted on our terms. Even if the technology is shared, our requirements are not those of other disciplines. We must avoid, for instance, the situation relating to archaeological science, the responsibility for which was devolved to NERC. 
External disciplines have advice to offer but they cannot be allowed to determine our research agendas. As a group the Arts must seek appropriate funding that allows infrastructural development. There has been a tendency in the past for "big science" to control dedicated computational facilities rather than the Arts. If we do not have appropriate funding, then we will fail to establish an appropriate pool of expertise within our disciplines and our research agendas will suffer as a consequence.

The nature of modelling behaviour is such that we require resources capable of modelling exponentially expanding data sets and the complexities of human action. In areas where we touch the physical sciences, the Arts must demand parity for our research with physical geography, geology and the Social Sciences. As a bottom line we have to be confident, and active, in our assertion of the significance of Arts and Arts visualisation. We are part of the larger visualisation market that feeds the cultural economy and this should be recognised.

\section{Conclusion}

In conclusion, we must acknowledge that large data and their use is a challenge for the Arts. However, this is not simply because visualisation is technically complex or even because it is expensive. Rather this reflects the fact that so much of our visual content is itself contentious. However, we cannot sidestep tension in interpretation as this may, in respect of multivocality and reception, be central to academic exploration. In such situations, sophisticated visualisation may well be the most appropriate route to investigate such phenomena. Following from this, if we do accept that complex visualisation is to be part of our academic strategy there can be no half measures in providing resource. Whilst it is good to share, and we have much to learn from other disciplines in relation to specific technologies, we must accept that responsibility regarding the relevance of visualisation technologies to the Arts, and the implementation of these technologies, is ours alone.

\section{Acknowledgements}

I would like to thank the following for their comments and suggestions when writing this paper - Paul Hatton, Meg Watters, Andy Howard, Keith Challis, Dr Henry Chapman, Ben Gearey, Helen Goodchild, Simon Fitch, Dr Ken Thomson, Dr Mark Jolly, Dr Lorna Hughes, Dr Sheila Anderson, Dr Stuart Dunn, Dr Roger White, Helen Gaffney, Professor Bob Stone, Eugene Ch’ng, Dr Ian Haynes.

\section{References}

[1] http://www.iaa.bham.ac.uk/Computing/HP_VISTA/HPindex.htm

[2] http://www.iaa.bham.ac.uk/research/opening/main.htm

[3] http://www.iaa.bham.ac.uk/bufau/services/3Dscan/Lidar.htm

[4] http://www.iaa.bham.ac.uk/research/filedwork_research_themes/projects/North_Sea_Palaeolandscapes/in $\underline{\text { dex.htm }}$ 